\title{
Reconstruyendo el entramado de una sociedad creativa. Estrategias para la formación de diseñadores en contextos de complejidad
}

\section{Galán, Beatriz}

\section{Resumen:}

La consideración de la palabra ideología en el contexto de la enseñanza del diseño, hace referencia a un contenido oculto, encubierto, respecto a los orígenes de la disciplina, su funcionalidad y convergencia con la configuración de la sociedad moderna capitalista. Ese contenido oculto es, ni más ni menos, la compleja trama de ligazones que une a los artefactos con la institucionalidad que los sustenta, con los valores y reglas que rigen la vida social, que asumió a la industria como dispositivo potente de producción de valores, cuya racionalidad fue consustancial a la idea del diseño, a su ética y finalidad, que era la extensión de los beneficios de la ciencia y la tecnología al conjunto de la población. Hoy, las fisuras de esta configuración social, impone una nueva conexión entre las prácticas y su sentido. Pero ese ocultamiento del sentido, esa mutilación de contenidos, se hace posible por unos modos de enseñanza, que a su vez, tácita o explícitamente, se encuadran en epistemologías que se revelan insuficientes. Este artículo que reproduce parcialmente, ideas de la tesis doctoral, "Reconstruyendo el entramado de una sociedad creativa", da cuenta de las primeras percepciones de los obstáculos epistemológicos de la disciplina para insertarse en contextos de complejidad, reconstruir la disciplina como programa de investigación, revelando su rol en la reproducción de la vida social sustentable.

Palabras clave: Diseño - obstáculo - sustentabilidad - investigación-acción - epistemología 
En 1985, al crearse las carreras de diseño, se hace más notorio el desenvolvimiento heurístico de la enseñanza y la necesidad de inscribir nuestra disciplina, el diseño industrial, en el ámbito de la investigación que iba presionando desde el contexto universitario, tanto nacional como internacional. La necesidad de contar con un modelo teórico de la actividad de diseño aparece como una necesidad del desarrollo disciplinar. Esta etapa heurística, es sumamente productiva en la creación de trabajos prácticos y estrategias de enseñanza. Pero la disciplina carecía de un discurso que la posicione en el sistema científico.

En la coyuntura en que se crea la carrera de Diseño Industrial, en la Universidad de Buenos Aires, las respuestas a problemas metodológicos surgidos del propio seno del pensamiento de diseño no contribuían a posicionar a la disciplina en el sistema científico y en las estructuras de transferencia nacientes. Existía la necesidad de explicar la disciplina, en su relación con la investigación.

El concepto de obstáculo epistemológico ocupa un lugar central en el pensamiento de Gaston Bachelard.

"Solo mediante el establecimiento de esta herramienta conceptual es posible comprender las causas de los dificultades, de los estancamientos y, aún, de los retrocesos en los procesos de construcción del conocimiento científico". (Camillioni, 1997, p. 11) Frente a la percepción del obstáculo, que es captado en una anomalía de la praxis, en una insuficiencia de las representaciones dominantes en una disciplina, es necesario colocarse en el lugar de la ruptura. Es el tránsito hacia al conocimiento científico, la construcción de un sujeto epistémico de argumentos fundados.

La frase "El saber, sustantivo o verbo?" (Rumelhard, en Camillioni, 1997, p. 61) condensa la noción de obstáculo generalizable a todas las disciplinas, en la medida en que el saber, el método, el artefacto sean considerados estructuras coaguladas, separadas de sus historicidad. Entonces estamos frente al obstáculo que enfrenta todo sujeto que se constituye en la comunidad científica.

"Volver sobre el recorrido, es lo propio de la enseñanza. Recorrer un camino, pero también saber cuál fue su recorrido". (Rumelhard, en Camillioni, 1997, p. 60)

"Las representaciones están mediadas por los contextos en que fueron construidas y los contextos lo están por la representaciones". (Camillioni, 1997, p. 29)

En su clasificación de los obstáculos epistemológicos, hay uno de los tipos vinculado directamente al mundo de los objetos, físicos, visuales, y cognitivos. Cuando el concepto da lugar a objetos técnicos, estos se transforman en obstáculos, porque solo visibilizan el concepto en el cuál fueron concebidos. (Camillioni, 1997, p. 57)

La ausencia del contexto en la enseñanza del diseño

Era necesario ampliar la base de comprensión de nuestra disciplina, centrada en los objetos, de los cuales, en la mayoría de los casos, desconocíamos su origen, las batallas ganadas y perdidas para poder concebirlos, producirlos, introducirlos y validarlos en el ambiente cultural. En 1994 (Galán, Poy, 1994), hicimos un diagnóstico en grupos de estudiantes avanzados de diseño, respecto a su capacidad de análisis y reflexión en torno a su actividad, a partir de restituciones verbales de sus procesos de trabajo y observamos escasas referencias al 
contexto y a la situación problemática. El pensamiento de los alumnos en su mayoría no podía despegarse del objeto. Si bien manejaban conceptos aislados, aparecían como restituciones posteriores de las decisiones, de escaso valor productivo. Lo que no podía leerse era el "objeto institucionalizado" como producto, lo que supone un sistema de anidamiento, de actores y relaciones, el sistema productivo, que es además resultante de un proceso de reproducción de la vida social.

El esfuerzo de la investigación era la construcción de un objeto modelo del producto y de sus contextos relevantes, que partiendo de un pre modelo avanza hasta la creación de un modelo enriquecido que facilitara la toma de decisiones. La construcción del objeto modelo, es un asunto central en la metodología de investigación desarrollada por Samaja. Samaja, sostiene que para conocer un objeto es necesario desbordarlo (Samaja, 2006, p. 167), lo que implica entenderlo en su contexto. La ontología de la complejidad, pone a disposición de las disciplinas una herramienta para comprender sus objetos, y enfrentar los obstáculos epístemológicos : para el diseño, en una perspectiva sistémica estos obstáculos son la noción de objeto, y la noción de autor. Los objetos, para nuestros estudiantes, circulan desprendidos de sus historia, naturalizados por los procesos de transferencia, el consumo, generando alienación más que cultura, ejerciendo una seducción y bloqueando la posibilidad de nuevos estrategias de diseño.

El concepto de epistemología ampliada

Consideramos que lo que el diseño necesitaba era ampliar las unidades de análisis bajo observación, centrándose en problemas reales, y especialmente, tomados del contexto local1. Diaz, en el contexto de la enseñanza de las ciencias en general, sostiene la necesidad de una epistemología ampliada, dado que, al recibir los estudiantes, una visión despolitizada y desarraigada de la historia de las ciencias, se monta "una gigantesca operación de encubrimiento" (Diaz, 2007, p. 21). La epistemología ampliada, es aquella que confronta al núcleo gnoseológico, "al que denominamos interno", con la supuesta exterioridad (Diaz, 2007, p. 22). Hay perspectivas que construyen hacia adentro y otras lo hacen hacia el entorno.

Sin embrago, también hay corrientes teóricas que exploran una alternativa a la polaridad y borran límites más que establecerlos,... Se trata entonces de saltar este muro teórico y sumergirse en las estribaciones, a veces caóticas, de los procesos cognoscitivos; en las indeclinables afecciones humanas y en la incidencia de los elementos no humanos que forman parte de ésta complejidad. (Díaz, 2007, p. 24)

Hacia la superación del obstáculo

El diseño, como disciplina vinculada a la acción, ha ensayado diversos modos de exportar ciertos aspectos de la práctica como objetos de estudio, a campos teóricos de mayor desarrollo a los efectos de iluminarlos y generar modelos que apoyan las prácticas profesionales. No obstante, el campo de los diseños, y el del diseño industrial en particular, tiene al pensamiento de diseño, como una corriente, que es a la vez epistemológica, teórica y metodológica, con autores asumidos por la comunidad disciplinar como sus pensadores, que desde recursos conceptuales contribuyen al desarrollo de las prácticas de diseño, parten de ellas, y finalizan también. De allí que el diseño aspire su propias representaciones enmarcadas en un pensamiento de diseño que abarque toda su complejidad. 
En nuestro programa de investigación sostenemos un modelo del proceso1, a partir de un camino iniciado por Simon (1978), desarrollado como ontología de la complejidad, por Samaja (2000, 2004a , 2004b), y continuado por Ynoub (2010), como semiótica en clave dialéctica, ontología de la complejidad o semiótica de la acción, aplicada a lo que Samaja propuso como una macrosemióticade los artefactos. Esta línea, constituye un enfoque transdisciplinar, que permite a las prácticas y disciplinas a repensarse desde su rol en la reproducción de la vida social, enfrentando los obstáculos epistemológicos que cada una enfrenta en el proceso de reinsertarse y repensarse en ambientes complejos. Fue implementada en la cátedra de Metodología y en la Investigación por B. Galán2, prosigue en el programa de investigación ( RED) IA3, y culmina en la creación de un Centro de Investigación de diseño para el desarrollo4 .

Disciplina y profesión. En busca de las raíces epistemológicas

Una disciplina es, para Camillioni:

Un campo de conocimiento sistemático, que se caracteriza por estudiar determinados objetos de conocimiento y resolver cierto tipo de problemas con ciertos métodos, y determinadas lógicas de descubrimiento, y de justificación e incluso de aplicación y por presentar un cierto discurso que también le es propio. (Camillioni, 2010)

Por otro lado, define la profesión es un conjunto muy amplio, casi infinito de habilidades que un sujeto puede seleccionar, aplicar y reproducir de acuerdo a una actividad, pudiendo ejercer la autocorrección de sus actividades, las que ejerce con autonomía intelectual y responsabilidad personal, responsabilidad que no puede delegar en otros. Adhiere también a una ética, es decir a una manera particular de ejercer estas habilidades, de acuerdo a juicios valorativos compartidos por su comunidad5 .

La epistemología "es la rama de la ciencia combinada con una rama de la filosofía",... "es el estudio de la manera en que determinados organismo o agregados de organismos conocen, piensan y deciden". (Bateson, 2001, p. 201)

La ontología se ocupa de lo que hay en el mundo, y según Bateson, la filosofía se ha ocupado de separar ambas nociones.

En la historia natural del ser humano viviente, la ontología y la epistemología no pueden separarse. Sus creencias (por lo común inconscientes, acerca de qué clase de mundo es aquel en que vive, determinarán la manera como lo ve y actúa dentro de él, y sus maneras de percibir y actuar determinarán sus creencias acerca de su naturaleza. El ser humano, pues, está ligado por una red de premisas epistemológicas y ontológicas independientemente de su verdad o falsedad últimas- se convierten parcialmente en autovalidantes para el. ( $\mathrm{J}$ Ruesch y G. Bateson, Communications, The social matrix of Psychiatry, Nueva York, 1951, citado en Bateson, 1998, p. 344)

Una disciplina debe intentar modelizar su objeto, asumiendo que el modelo es una interface entre la experiencia y la teoría. Si consideramos que ese sujeto epistémico, es aquel que es capaz de construir modelos, como medidores de la teoría y la experiencia, entonces, la cuestión ontológica se vuelve central en el desarrollo disciplinar. 
Nuestra experiencia nos fue mostrando que esta complejidad, no puede quedar abarcada desde una malla curricular estanca, sino que es necesario apelar a un dispositivo que articule estratégicamente la teoría con las prácticas. En términos institucionales esto equivale a vincular la universidad con la sociedad, y no sólo a la investigación, sino al taller de diseño, en el que se forman los valores y categorías conceptuales con que nuestra profesión construye sus relatos. La práctica profesional y la formación académica del diseño en todas sus variantes a nivel internacional y local siguen aún centrada en el objeto, sin distinguir aún en su modos de existencia en el proceso de desarrollo y en la vida económica. $Y$ esto es así, por que las reglas que rigen la actividad práctica, se han establecido a partir de ciertos aprendizajes, que se olvida, quedando como coagulaciones, que solo se ponen en duda, y se revisan, cuando se desafían contextos nuevos y se revelan insuficientes.

Cualquier estrategia de modelización que tienda a reemplazar una descripción de proceso por una de estado, borra la huella de su gestación y crea un obstáculo epistemológico, en tanto que el proyecto es proceso.

Una estrategia teórica y representacional para la gestión de diseño debe:

- Ser dinámica, registrar procesos

- Exhibir las unidades de análisis involucradas

- Incluir al contexto normativo, no solo como una fuente de perturbaciones, sino también

- de estímulos y oportunidades,

- Exhibir un operador ( modelo que diera cuenta de las relaciones, los elementos y las operaciones),

- Incluir al sujeto que le asigna sentido

- Y a la comunidad como contexto normativo

- Poner el desenovolvimiento social como contexto-proceso : el desarrollo

La estrategia del Programa de investigación

Elegimos poner en suspenso la atención fija en los objetos, para hacerlo en las demandas sociales, y colocar a las experiencias de vinculación como unidades de análisis, experiencias que sostengan y enriquezcan las prácticas profesionales emergentes. Fijamos premisas y condiciones de carácter ético para involucrarnos en experiencias de vinculación con el medio desde la universidad:

- El cambio tecnológico como escenario y proceso subyacente,

- La investigación acción participativa y la construcción comunitaria como metodologías,

- El desarrollo endógeno como objetivo, 
- El diseñador como animador cultural

- La cultura del producto como eje estructurante del tejido social

- El territorio como sistema complejo, en sentido socioecológico, incluyendo los distritos que conforman el sistema urbano, y los flujos horizontales que los relacionan para logra un desarrollo equitativo y equilibrado.

- El desarrollo como matriz conceptual y por lo tanto, debe trascender a la visión disciplinar.

El desarrollo como matriz conceptual

El diseño para el desarrollo local, (Margolin, 2006, Oosterlaken, 2009 Buchanan, 2009)6 , ha traído localmente, al campo del proyecto, un cambio de valores y ha corrido las fronteras disciplinares, anclando las prácticas en los territorios. Cuatro ediciones de Jornadas de alcance nacional y latinoamericano7 , y un conjunto de eventos latinoamericanos, han validado esta perspectiva y han contribuido a apropiarse del concepto de innovación con un sentido estratégico. El enfoque del diseño para el desarrollo, trascendió incluso la retórica de la innovación asociada a la competitividad, y replanteó el concepto mismo asociándolo al campo de las innovaciones sociales, considerando especialmente la actividad de las comunidades locales en su enfrentamiento de las marginaciones en sus diversos aspectos. Esta actividad innovadora, de carácter social, posibilitada por las comunidades creativas potenciadas por redes ha sido puesta de relieve por Manzini (2006) como preludio de una nueva industrialización sustentable. Y a nivel regional, ha sido destacada en el Foro de Innovación de las Américas8 , como una actividad socialmente extensa, basada en innovaciones sociales, no restringida a los países desarrollados (Brook, 2011), que combina conocimientos "modernos y no modernos", con desigual reconocimiento en el ámbito político, pero imprescindible para dar respuestas eficaces a las necesidades sociales (Bernal, CEPAL; 2011).

Globalización y diseño. Una oportunidad para la reflexión

En los escenarios de la globalización las unidades productivas, las organizaciones de la sociedad civil y las comunidades se ven obligadas a confrontar sus posibilidades y recursos, a reordenar sus patrimonios materiales o simbólicos, para enfrentar contextos transculturales y complejos. La gestión estratégica de diseño, es un acoplamiento estructural entre una realidad productiva local, que es objeto de la gestión, y un contexto externo, representado por los escenarios de la globalización en los que es necesario acreditar los activos locales. Nuestra hipótesis es que la cultura del producto, actúa como articulador del tejido social, se sitúa en el acoplamiento estructural de oferta y demanda, organización y contexto, articula el territorio en redes organizadas en escalas, tiene un carácter emancipador, generador de autonomía y sustentabilidad. El proyecto se propone, describir, sistematizar y modelizar las diferentes estrategias de transferencia de diseño para evaluar sus impactos, desarrollando variables e indicadores, a partir de la formación de un centro como dispositivo interdisciplinario para construir teórica y metodológicamente este campo de conocimiento. (Galán, 2006)

La tecnología ha venido a desempeñar un rol en la formación de las categorías y patrones con que pensamos nuestra cotidianeidad. La emergencia, a mediados del siglo XX de una tecno cultura, con un fuerte sesgo en lo social y en lo político, viene a dejar en desuso las visiones fragmentarias de la misma, cambiándolas por una visión integrada, superadora de las visiones entre teoría y práctica, artificio-naturaleza, o objeto-sistema. 
El fenómeno de la innovación, redefine la trama social en el paradigma de la red. Estas sientan un territorio propio, que atraviesa las fragmentaciones a que nos tiene habituada la ciencia tradicional. Los problemas son a la vez, naturales, sociales y discursivos, y resulta imposible reducirlos a uno de sus aspectos o dimensiones. Los vastos programas de Investigación empeñados en superar las fragmentaciones, terminan por designarse como Ciencia y Cultura, o Ciencia, Tecnología y Sociedad, es decir, como la suma de los territorios que intentan asociar. Decidirse por las redes, es asumir que iremos a donde nos lleven, que estamos dispuestos a traspasar las fronteras disciplinares, porque esto es necesario para recuperar el sentido de los fenómenos, la unidad de nuestra experiencia y por que el propio sentido de nuestras disciplinas de origen ésta entrañado en ésta construcción más compleja. Las condiciones en que se verifica la difusión de la técnica generan obstáculos epistemoló- gicos específicos que se manifiestan en los procesos de difusión: los patrones culturales y valores de las comunidades de origen. Es necesario enfrentar éste fenómeno, con una actitud de alerta intelectual para restablecer el sentido de la técnica como factor de ajuste entre necesidades y recursos. Pero estas necesidades deben ser reinterpretadas adecuadamente en un marco valorativo local y en una perspectiva socialmente sustentable.

La innovación estratégica surge de una actitud de complementariedad tecnológica madura y no de mero reflejo imitativo de la innovación en los países de origen. Generalmente cuando se habla de innovación, se subvaloran los esfuerzos de adaptación desarrollados en los contextos de asimilación que redundan en una contribución a la calidad de vida local. Creemos que el diseñador, especialmente en contextos de asimilación tecnológica, tiene un rol activo y decisivo en estos procesos de apropiación.

Los méritos explicativos de la innovación consisten en instalar el paradigma de conocimiento distribuido que desplaza una concepción ingenua, muy arraigada en el medio del diseño, que es el diseño de autor.

Reposicionamiento y valoración del conocimiento proyectual

A su vez el pensamiento proyectual ha sido abordado y valorizado como actividad estratégica del desarrollo local. Se lo asocia a un tipo de inteligencia creativa, de carácter estratégico. El posicionamiento del diseño en la cultura contemporánea se realiza sobre su competencia para la construcción de poder simbólico, competencia que proponemos al servicio del desarrollo social sustentable. Tal como afirma María Ledesma, si bien muchas disciplinas "proyectan", solo una, el diseño, ha hecho del proyecto su fundamento epistemológico. (Ledesma, 2007)

Si bien proyectar no es propio de arquitectos y diseñadores, hay algo sustancial que hace diferencia y que se relaciona con lo anterior: es el único campo del conocimiento que lo reclamó como constitutivo, como modo de pensar y de idear. (Ledesma, 2005)

Retomando una evolución que escindió de la experiencia intelectual, dice Ledesma:

Pero, en este proceso, es justamente el diseño el campo que, desde entonces, ha quedado a mitad de camino entre la creación de un mundo simbólico y la participación activa en la producción y transformación del mundo económico, desgarrado en ese mundo que se construía sobre su desgarro. (Ledesma, 2005, p. 42) 
Proponemos a los desarrollos de Samaja, sobre la semiótica en clave dialéctica, y otros aportes que van en el mismo sentido, como marco para le reconstrucción del objeto del diseño como disciplina. Retomando ésta perspectiva (Samaja, 2000, 2004), las sociedades humanas se han reproducido suprimiendo y superando estadios, desde una dimensión biológica, pasando por una comunal, posteriormente estatal, para culminar en una formación del estado moderno con la sociedad civil como actor protagónico (Samaja, 2004, p. 56). En cada una, han predominado prácticas reproductivas y productivas, inherentes y consustanciadas con ciertas formas de subjetividad (Samaja, 2004, p. 67). El diseño como acción planificada se introduce en las prácticas productivas superando las formas preindustriales de producción. Se impone juntamente con la ciencia como actividad codificada, y con la tecnología, que en ésta etapa de la civilización ocupa un lugar como mediadora comunicacional (Samaja, 2006). La innovación, en esta perspectiva, es el privilegio otorgado a las operaciones de transformación, sobre los patrones conservadores pre-industriales.

Sostiene que la formación del sujeto en sentido epigenético9 atravesó una serie de saltos de complejidad, que tuvo una forma social dominante, y una forma de semiosis protagónica para cada configuración social, la cual se constituyó como parte de la supresión y superación de las anteriores en un proceso que Samaja llama fenómenos de la libertad.

Por lo antedicho, en cualquier práctica social conforme a la ontología social, encontramos:

- Una dimensión biocomunal

- Una dimensión comunal cultural

- Una dimensión ecológico política

- Una dimensión societal (tecno económica) (Samaja, 2004, p. 131)

Que se presentan como dimensiones de lo real, y etapas del proceso reproductivo. Esta visión de los sistemas complejos reproduce un orden constitutivo regulativo. (Samaja, 2004, p. 108) Junto con la innovación, aparece la acción planificada: las sociedades se apropian del futuro, conquistan sus entornos, neutralizan sus amenazas, explotan sus oportunidades o expanden sus influencias. Esta impronta está fuertemente guiada por la reproducción de ciertos patrones de normalidad, cuyos comportamientos se sujetan a valores guiados por interpretaciones de la vida social.

En tanto que en cada etapa subsisten las configuraciones de prácticas que han sido superadas, nuestra realidad productiva encuentra los rasgos de aquellas praxis anteriores, coexistiendo en universo técnico que adquiere sentido solo sobre la reconstrucción histórica de su gestación. Esta capacidad de reflexión-acción sobre la cultura técnica califica al ciudadano en el ámbito cultural contemporáneo, lo habilita para desarrollarse como sujeto en un ambiente simbólico culturalmente diverso y complejo.

Estructura y proceso. Su significación en la relación con los objetos técnicos

Samaja distingue entre producción y reproducción, la primera sugiere génesis, proceso, y la segunda estructura, la que tiende a coagular en productos, objetos, métodos, etc. La semiótica en clave dialéctica se interesa por los orígenes en la formación de las reglas, que sustentan nuestra vida en comunidad, originalmente inundadas de 
sentido por experiencias comunes, frecuentemente olvidadas, ocultadas por las estructuras resultantes. La operación "recaída en la inmediatez" permite concebir la relación entre la producción y la estructura, como una transposición en la que el orden de los componentes de la génesis se invierte en el de la estructura (Samaja, 2004 , p. 105). Lo considera un fenómeno clave por el cual, el resultado de un proceso, se presenta a la conciencia como punto de partida, borrando las huellas de su historicidad.

El concepto de "recaída en la inmediatez", tomado de Hegel y reinterpretado por Samaja, es el efecto por el cual el proceso, la génesis, se olvida, y la conciencia retiene la estructura, una característica que condiciona la dinámica del conocimiento. La reflexividad intenta enfrentar este fenómeno, reconstruyendo el sentido: para esto inscribe los indicios, las palabras, los hechos, los objetos, en su historia formativa.

Este fenómeno tiene consecuencias importantes para el diseño, ya que, en procesos de cambio, esta presencia de los objetos, se constituye en obstáculo para la concepción de nuevos objetos, nuevas institucionalidades y nuevas racionalidades que satisfagan las demandas sociales. Desde ya es también una ventaja, la disponibilidad del objeto, su capacidad para concentrar y hacer disponible el conocimiento humano, canalizarlo en la vida cotidiana, e ingresar al universo cultural , no sería posible si no existiera esta capacidad de coagulación del conocimiento. Pero al mismo tiempo, se transforma en obstáculo cada vez que el contexto impone reconfiguraciones del mundo de los artefactos de carácter sistémico, y en particular cuando hace falta cuestionar el universo de valores en que anida el objeto, para dar lugar a innovaciones de carácter abrupto. La semiótica en clave dialéctica propone reconstruir esta génesis (Samaja, 2006, p. 116). Este es el tipo de obstáculo que enfrenta las actividades de investigación acción, reinician el ciclo de comprensión, comenzando por los individuos, a partir de comprender sus comportamientos particulares en relación a universos de observación. Introduce una visión procesual, dinámica, lo que deriva en una reconstrucción del sentido, "apunta críticamente contra la naturalización y la reificación". (Samaja, 2004, p. 161) La recaída en la inmediatez, es a su vez, un componente necesario de la reproducción social, pues permite trabajar con las estructuras productivamente, en el mundo de la técnica, la cuasi descomponibilidad de los sistemas, potencia las combinatorias y las dinámicas de creación.

En ese sentido, la semiótica en clave dialéctica define las disciplinas en relación a un mismo proceso reproductivo de la vida social permitiendo que se puedan construir fácilmente relaciones de carácter transdisciplinar. Al poner un nuevo eje a la reflexión, las disciplinas deberán confrontarse en un mismo marco de referencias en relación a la reproducción de la vida social sustentable. Esto sienta las bases de una visión del diseño diferente, para la cual el desarrollo entendido como proceso de reproducción de la vida social, es su marco y la materia de su accionar. En el terreno pedagógico cuyo objetivo es reproducir el diseño como disciplina y como práctica o conjunto de prácticas, puede denominarse una pedagogía del caos (Díaz, 2007, p. 78)10 que enfrenta las crisis y trabaja a partir de ellas, que no solo se hace cargo del diseño de objetos, si no de la historia formativa que inunda de sentido el mundo de los objetos técnicos. En lo institucional, deriva en un proyecto universitario abierto a la comunidad, interactivo y dialógico, que se vuelca sobre el territorio en busca de éstas conflictividades, asumiendo la responsabilidad social universitaria, y buscando la formación de un nuevo intelectual, con una imaginación didáctica y una vocación democrática.

"Un trabajo de imaginación epistemológica y de imaginación democrática con el objetivo de construir nuevas y plurales concepciones de emancipación social sobre las ruinas del proyecto emancipador automática del proyecto moderno". (De Sousa Santos, 208, p. 164) 
El proyecto es la acción a través de la cual los colectivos sociales asumen la superación de obstáculos en diversos grados y construyen horizontes, a modo de zonas de desarrollo remoto (Marina, 1993, p. 336). Esa racionalidad hoy se resume en la construcción de la sustentabilidad como perduración de un sistema en el tiempo11. Esta inteligencia proyectual, reconocida contemporáneamente por autores como Ladrière (2001), Nonaka y Takeuchi (1999), Marina (2000), surge en la práctica comunitaria, es sistematizable, se incorpora en las instituciones como una función específica (Nonaka, 1999), y se reproduce en la Universidad.

El conocimiento proyectual es un conocimiento estratégico para las condiciones de complejidad e incertidumbre que caracterizan la existencia contemporánea. Podríamos asimilarlo a la inteligencia adaptativa (Piaget, 1997), la construcción de acoplamientos entre sujetos y contextos, entre expectativas y recursos. Cuenta entre sus competencias la capacidad de leer los contextos, desarrollando una sensibilidad específica, de aprovechar oportunidades y no solo de enfrentar perturbaciones. Se interpreta como una inteligencia creadora de naturaleza superior. Para Antonio Marina "crear es someter las operaciones mentales a un proyecto creador". (1993, p. 151)

Simon (2006), construye las bases epistemológicas de este conocimiento, estableciendo las condiciones para su modelización. Para el autor:

Diseña todo aquel que concibe un curso de acción que a partir de una situación dada alcance un desenlace ideal. La actividad intelectual de producir artefactos materiales no es radicalmente distinta de aquella de quien receta remedios para un paciente enfermo, ni la de quien concibe un nuevo plan de ventas de una compañía o una política de bienestar para un estado. El diseño entendido de este modo, constituye la clave de toda formación profesional, la marca distintiva de las profesiones frente a las ciencias. Concierne, sobre todo, el proceso de diseño a las escuelas de ingeniería, así como a las de arquitectura, negocios, educación, derecho y medicina. (2006, p. 133)

El diseño trata "acerca de como deberían ser las cosas con la concepción de artefactos que sirvan para alcanzar una meta" (Simon, 2006, p. 137) y por tanto, el autor señala la necesidad de nuevas y específicas formas de inferencia, de acuerdo a una lógica del deber, una lógica imperativa la ciencia del diseño, busca según el autor, extender los principios de la computación, de la inteligencia artificial y la investigación operativa. La dinámica del diseño busca establecer los mundos posibles, los estados de una entidad que satisfacen las condiciones del mundo externo, en una lógica de optimización. Establece las bases para una representación sistémica del proceso de diseño a través de los atributos de los sistemas complejos:

1. Su cuasi descomponibilidad, que genera ventajas en la utilización productiva de tales estructuras. Se trata de aquellos sistemas en que las relaciones intracomponentes son más fuertes que las relaciones intercomponentes.

2. Su arquitectura jerárquica, en la medida en que las entidades se relacionan con sus contextos, con los que buscan establecer acoplamientos óptimos. 
Le asigna al diseño la misión de construir una zona común entre las culturas, y lo define como un artefacto evolutivo. Indaga en las condiciones en que se desenvuelve el diseño social, exponiendo el principio de racionalidad limitada, como "el sentido de racionalidad en situaciones en que la complejidad del entorno es mucho mayor que la capacidad computacional del sistema adaptativo"12.

Nonaka extiende el pensamiento de Simon incluyendo al conocimiento tácito, "el conocimiento que puede expresarse con números y palabras es la punta de iceberg del cuerpo total del conocimiento" (Nonaka, Takeuchi, 1999, p. 67). El modelo de Nonaka nos plantea un eje epistemológico, que marca el tránsito entre el conocimiento tácito y el conocimiento explícito, y que cumple con los ciclos de socialización, combinación, exteriorización e interiorización, y un eje ontológico, que enfrenta ciclos cognitivos cada vez más amplios, en la escala individual, grupal, organizacional e interorganizacional (Nonaka, Takeuchi, 1999, p. 83). El conocimiento tácito movilizado se amplifica a través de recortes organizativos desde el nivel individual hacia comunidades cada vez mayores, formando una espiral de conocimiento, que comienza por los por individuos, los grupos, las organizaciones, y los niveles supra organizacionales. (Nonaka, Takeuchi, 1999, p. 63)

Empieza por la creación de un campo de interacción. Este campo permite que los miembros de equipo compartan sus experiencias y modelos mentales. Segundo la exteriorización empieza a partir de un diálogo o reflexión colectiva significativos, en los que el uso de una metáfora o una analogía apropiada ayuda a los miembros a enunciar un conocimiento tácito oculto, que de otra manera resultaría difícil de comunicar. Tercero, la combinación da comienzo con la distribución de redes del conocimiento creado y el conocimiento existente de otras secciones de la organización, cristalizándolo es un nuevo producto, servicio los sistema administrativo. Y cuarto la interiorización se origina en el aprender haciendo. (Nonaka, Takeuchi, 1999, pp. 80-81)

La primera fase da un conocimiento armonizado, la segunda un conocimiento conceptual, la tercera un conocimiento sistémico, y la cuarta operacional. (Nonaka, Takeuchi, 1999, p. 80) Tanto Nonaka como Marina, intentan poner de relieve la capacidad de los sistemas inteligentes para generar su propias metas, lo que los coloca más allá de una mera inteligencia adaptativa de tipo pasiva. Para Antonio Marina "Crear es someter las operaciones mentales a un proyecto creador" (2003, p. 151). Sustenta la idea de valores y sentimientos universales sobre las que es posible construir una plataforma de sustentabilidad. El autor reclama una "inteligencia en contexto", capaz de poner al conocimiento baja la modulación de la ética, lo que él llama "inteligencia creadora", es capaz de construir las condiciones para una felicidad objetiva en la que se pueda desarrollar la felicidad subjetiva. (Marina, 2000, p. 132)

De una epistemología conjuntista a una epistemología tríadica

Samaja propone que la ciencia occidental ha estado dominado por una idea cojuntística, la idea de la realidad como una colección de cosas, lo que asimila a una concepción positivista. El autor recorre los aportes de la semiótica contemporánea, en clave dialéctica, asimilando la noción de signo en el terreno de la semiótica, al de dato en el de la metodología. Samaja reinterpreta la terceridad peirciana, no como un tercer elemento : la semiosis supone un tercer "modo de ser" para incluir el contexto normativo, "que hace posible el vínculo representacional" (Samaja, 2000)13. Esta terceridad entendida como un "tercer modo de ser", y no como un tercer elemento, es un salto ontológico y el engendramiento de una jerarquía, definiendo una organización14. Considera así a Peirce y a De Seassure (Samaja, 2000, p. 15) como los padres de una ontología de la complejidad. 
El primero por su concepción triádica del signo y el segundo, a través de "la noción de 'valor', como sistema de diferencias, el cuál supone a la 'Lengua', y esta al 'ser social', como base real del sistema normativo que engendra todo signo" (Samaja, 2000, p. 15). Esta trascendencia de los objetos, en el movimiento reflexivo, la recomposición de su historicidad, es la clave para la reflexividad, para introducir la mirada dinámicas, procesual, histórica y a la vez estructual y sistémica.

Samaja interpreta la terceridad como un "modo de ser", que incluye al contexto normativo que hace posible el vínculo representacional (2000, p. 14). Existe un marco regulatorio y normativo social, ya no individual, que permita que ese sentido se perciba. Pero esta legitimidad de la semiología como marco para descifrar la naturaleza del objeto y la gestión nos permite el reconocimiento e inclusión de la subjetividad, al sujeto y al contexto social plenamente incluido en el modelo.

La epistemología tríadica, tal como la expone Samaja, se relaciona con la actividad instituyente del proyecto. Si el proyecto se establece sobre una situación a cambiar, concluirá con una situación inicial transformada, un objeto nuevo o modificado, que ha de ser validado por una comunidad de intérpretes.

Los objetos como fragmentos de la vida social

En un dimensión comunicativa los objetos presentan atributos absolutos, relativos y contextuales (Samaja, 2000, p. 163).Los primeros son aquellos que no dependen de un sujeto, su materialidad por ejemplo. Los relativos introducen al sujeto que les asigna un sentido, sentido que a su vez es validado por una comunidad de intérpretes. En el enfoque constructivista sujeto y objeto se construyen conjuntamente y tratándose de una dimensión de comunicación, se construye en la historia de procesos de semiosis anteriores. A su vez, es cancelando el proceso, que los objeto se presentan a la conciencia como estructuras coaguladas, para facilitar una dinámica productiva. El proyecto, y más específicamente, las experiencias de transferencia de diseño se instalan en este momento particular en que se reconstituyen en la acción, la primera relación de sentido establecida entre sujetos, objetos y reglas, éstas últimas evocan a la comunidad. Por lo tanto, las experiencias de transferencia de diseño, no solo reconstruyen los orígenes de las reglas que guían nuestros comportamientos en relación a los objetos técnicos, si no las creencias más profundas, que subyacen a esos comportamientos. Este acto de juntar lo que se separó es un "nuevo comienzo", promueve una comprensión profunda, el surgimiento de un renovado espíritu científico que se abre paso entre las categorías coaguladas o los modelos establecidos y aceptados en la disciplina.

Los rasgos absolutos (primeriad) son "aquellos rasgos constitutivos de un objeto, según los elementos que trae de su historia anterior recaida en la inmediatez". (Samaja, 2000, p. 163) Los rasgos relativos (segundidad) "son aquellos que determinan a un objeto en relación a otros objetos".

Y los rasgos contextuales (terceridad) en tanto es un sub-objeto de un objeto de nivel superior, que Samaja designa como la comunidad de usuarios, jugando un rol similar que el átomo juega en relación al electrón, el organismo al órgano. Tomando como ejemplo un destornillador, menciona:

Desde esta perspectiva, la comunidad de usuarios no debe ser imaginada como un observador externo, sino como un rasgo mismo de un objeto complejo que incluye usuarios de destornilladores y destornilladores en una misma totalidad; en una misma Cosa (la cosa social). Este objeto complejo opera también causalmente (pero no 
con una causalidad sustancial molecular, si no funcional), sobre esa materia de celulosa y metal, siendo entre otras cosas, la razón de su forma, y de sus operaciones reales, de los lugares que ocupa, de la forma cómo se desgasta, de las interacciones en las que se encuentra predominantemente... hasta que un buen día deja de ser destornillador , con la misma procesualidad con que el corazón deja de ser corazón y el hidrógeno deja de ser agua. (Samaja, 2000, p. 164)

Esta descripción genera una arquitectura de información, basada en la percepción de unidades de análisis complejas en todas las escalas de observación, jerárquicamente organizadas, unidas entre sí por relaciones funcionales, lo que puede ser descifrado por la semiología en clave dialéctica. Sin la reconstrucción del contexto, no hay inteligibilidad, no hay semiosis.

La modelización de la gestión de diseño. Modelo y premodelo

Para Ladrière, la teoría es la descripción del modelo (1978, p. 39). El modelo es para el autor:

Un objeto complejo, de naturaleza ideal, considerado (al menos provisionalmente), como una aceptable representación esquemática del objeto estudiado. La teoría es un conjunto de proposiciones que describe las propiedades del modelo y permite hacer razonamientos a propósito de él; por ejemplo, predecir su comportamiento futuro o prever cómo reaccionará si se modifica su comportamiento de tal o cual manera. (1978, p. 39)

Ladrière sostiene que la acción, supone una "preconcepción modelizante", un a priori de inteligibilidad sugerida por informaciones previas de los objetos reales. Esta capacidad premodélica es importante en el caso del diseñador como sujeto práctico, que pone en juego su capacidad heurística. En la premodelización hay una ontología, que da cuenta de entidades concretas, y de sus relaciones. El corte analítico radica para el autor, en las interconexiones y relaciones entre el cuerpo y los dispositivos naturales o artificiales con los que esta emparejado. Para Ladrière un modelo supone un operador, es decir, un modo de acción capaz de transformar un estado en otro; operación de naturaleza formal, es decir, no depende de la sustancia del objeto explicado. Define una operatoria, es decir, explica relaciones entre entidades, es tematizable, es decir, aplicable a diferentes objetos de conocimiento, es generalizable a otros fenómenos, y está inserta en una red operatoria que puede ser extendida. (1978, p. 39)

La actividad proyectual, en tanto acción, es premodelizante. Ladrière (2001, p. 42) sostiene que las ontologías subyacentes en la acción preceden la construcción de objetos científicos. Más adelante nos referimos a la acción y su rol en los procesos de semiosis otorgándole a la transferencia un rol de reconstrucción del sentido original de las reglas.

"En la pre-comprensión modelizante, hay subyacente una verdadera ontología, es decir, un sistema de interpretación de la realidad que da cuenta de ésta en términos de entidades concretas, caracterizadas con precisión por sus propiedades intrínsecas y por sus interrelaciones”. (1978, p. 41)

Los modelos son también artefactos cognitivos. Para Rodriguez Barros:

La modelización se plantea como estrategia creativa, , comunicativa y cognitiva, que posibilita comunicar y visualizar hipótesis, formales, estructurales y funcionales de un proceso de diseño. En tanto que la simulación se 
presenta como la experimentación simbólica del modelo, que facilita la combinación entre hipótesis teórica y experimentación para su validación. (2007, p. 40)

\section{Los modelos organísmicos}

Los modelos que representa a los sistemas de éste tipo, son las matrices organísmicas, en las que las unidades de análisis se relacionan entre si como partes de un todo (Ynoub, 2010). La unidad de análisis de la gestión, la operación elemental, es una intervención, una acción de transformación ejercida en las variables de una unidad de análisis, en algún nivel del sistema, produciendo una conmutación en los valores de esa variable con consecuencias sobre las unidades contiguas. El modelo permite construir los mundos posibles, es decir, las posibilidades lógicas, contrastarlas con las empíricamente realizadas, las subjetivamente deseadas, y las intersubjetivamente posibles. En el curso de la gestión, una totalidad va a ser desestructurada y vuelta a reestructurar con nuevas informaciones. En una dimensión sintáctica, el diseño organiza la redundancia, en unidades inteligibles sobre algún lenguaje formal. En una dimensión semántica, organiza unidades de significado, que es uso en una dimensión pragmática cuando alguien se apropia con un fin determinado. Esta relación de imputación de sentido se construye en un contexto, la comunidad de intérpretes y usuarios de los bienes que valida esta construcción. El diseño es una gestión con capacidad de construir poder simbólico. En un aspecto discursivo y argumentativo lo hace como disciplina, teniendo a la comunidad científica como comunidad de comunicación y a través de los objetos, artefactos y productos, como profesión y con la sociedad como comunidad de comunicación.

La estratificación de los modelos y el tipo de inteligibilidad que habilitan, se basa en que las entidades involucradas se han conformado en una historia común. Si el proyecto, es el proceso que partiendo de una situación insatisfactoria, avanza hacia una zona de deseo, es necesario que estos modelos reflejen, ese proceso formativo común y esto se hace a través de un contexto-proceso. El desenvolvimiento de la vida social, representado por una narrativa de desarrollo que comparten los integrantes de la comunidad involucrada.

\section{La función con principio organizador15}

El objeto del diseño es el desarrollo de interfaces entre sujetos y contextos siguiendo una lógica de optimización. El diseño se basa en el concepto de función como principio organizador. El principio "el todo es más que la suma de las partes", organiza los sistemas complejos, conformados por unidades relacionadas por ligaduras funcionales, esto es, que ajustan su comportamiento para satisfacer condiciones impuestas por las totalidades en las que anidan. Estas ligaduras funcionales se comportan de acuerdo a relaciones de causación recíproca. Esta causación recíproca se establece al interior de las unidades (intra), ya sean productos o unidades productivas, entre unidades de un sistema (inter), y entre las partes y las totalidades orgánicas en las que anidan (trans). Los modelos que reflejan esta complejidad son las matrices organísmicas, en las que las unidades de análisis aparecen conectadas por relaciones de tipo parte-todo (Ynoub, 2010). La afinidad o pertinencia de unas partes en otras, se expresa como omnipresencia del sistema, como memoria, y autoconciencia en el caso de los sistemas sociales (los objetos del diseño lo son). Se manifiesta como un efecto regulante en sentido descendente y como un efecto productivo en sentido ascendente. Solo la formación del sistema en una historia común permite que esta impronta se exprese en cada una de las etapas/estratos del sistema. 
Los diseñadores estamos familiarizados con estas dinámicas, en la medida en que un componente debe satisfacer las reglas de unidad de un producto, éste su vez, debe satisfacer las condiciones de pertenencia a una familia de objetos. A su vez las familias o líneas deben satisfacer condiciones de pertinencia en relación con las colecciones, las colecciones deben responder a los segmentos cualitativos de una demanda de productos, y finalmente, ésta deben responder estructuralmente a la lógica de desarrollo de una unidad productiva, a las exigencias de un circuito cultural, en un sistema productivo definido. A medida que se recorren los estratos involucrados en una gestión de diseño, comprobamos que el tipo de entidades varían en su misma naturaleza, y que los objetos se constituyen conjuntamente con los sujetos que les asignan determinados sentidos y se apropian de estos sentidos en función de un fin. Esta función reproductiva es necesaria en todos los colectivos estructurados, organizados por reglas donde unas entidades desarrollan solidaridades funcionales entre las partes.

\section{La función como principio organizador}

La función es el tipo de relación que organiza los colectivos estructurados, y es por lo tanto la base del sentido común. En los sistemas sociales, las conductas funcionales, por las cuales los individuos se ajustan a las instituciones a las que pertenecen (Waddington, 1960, p. 69) se realiza a través de emociones éticas. Con diferentes grados de pertenencia y sufrimiento en algunos casos, los individuos se adaptan a sus ambientes institucionales a través de emociones éticas. Pero al mismo tiempo, su condición de sujetos de proyecto los habilita a modificar las condiciones cuando se perciben como perturbadoras o afectan a la vida o a la integridad de las totalidades o de las partes constitutivas. Waddington (1960, p. 63), sostiene que hay un conocimiento superior que llama sabiduría capaz de cuestionar las éticas subyacentes en los sistemas sociales y productivos. Samaja muestra que en la reproducción de los seres humanos se presentan, además de las dimensiones de reproducción de todo ser viviente, la reproducción de la autoconciencia, como sujeto que "se constituye en su relación con los otros"16 a partir de pactos preexistentes, la reproducción de las relaciones materiales y jurídicas que los integran en una totalidad supracomunal que preserva los vínculos de las diversas comunidades con sus ambientes territoriales de desarrollo, y la reproducción de los sistemas de los objetos, a través de los procesos de producción, distribución, intercambio y consumo de valores. (Samaja, 2004, p. 96)17

La disciplina y las prácticas emergentes y los modelos

La representación del objeto modelo de investigación pasa a ser una cuestión clave del diseño, como mediador entre la experiencia y la teoría del proyecto. Este proceso necesita (para nutrirse y a su vez nutrir) de la investigación acción para la construcción de la teoría. Señalamos que el movimiento que entraña la actividad de transferencia en los bordes de las instituciones universitarias, es la base de la reflexividad; este regresar sobre la historia recontextualiza la acción, para reinterpretar sus fines, entender las actividades en contextos de actividades, interpretar las prácticas individuales por sus rasgos particulares, formando parte de universos de observación, es la base misma de la formación de las categorías con que describimos la realidad. La transferencia es el ámbito que encuadra pequeñas experiencias de ruptura de los modelos establecidos, para promover la toma de conciencia, el salto cognitivo a la complejidad. Los modelos deben ser revisados, y la experiencia activa la quiebra y la acción precede a esta ontología, sistémica, local y compleja. 
Para Samaja, es necesario distinguir entre diseño, proyecto y proceso. (2004, p. 48)

El diseño (para Samaja, se refiere al diseño de la investigación) se refiere a los aspectos que podemos controlar. Diseño de la programación o diseño de la acción, la que resume en el marco lógico. (2004, p. 12)

El proyecto es (en este caso) una formalización que se representa a través del marco lógico de la acción, un criterio modélico que satisface las exigencias de los sistemas administrativos. El proceso, es la vida misma, aquello por lo cual encuentra justificación el proyecto, pero que lo desborda ampliamente en su complejidad. Samaja, toma de Merleau-Ponty el concepto de "mundo de la vida" y lo define como ese mundo de la praxis anterior a la reflexión y al establecimiento de la ciencia como segunda construcción de lo real. (Samaja, 2004, p. 48)

De allí que el autor asigna tanta importancia al mundo de la vida, que en la investigación se relaciona con la biografía del investigador, con sus vivencias, en un estado precomprensivo y premodélico. Sin embrago, es esta capacidad precomprensiva, lo que hunde las raíces de la investigación en el mundo de la vida, iniciando un proceso dialéctico de construcción ascendente hasta llegar al objeto modelo.

Todo el universo de la ciencia está construido sobre el mundo vivido, y si queremos pensar la ciencia misma con rigor y apreciar exactamente su sentido y su alcance, nos es menester despertar toda esta experiencia del mundo de la que la ciencia es su segunda expresión18.

La racionalidad técnico científica ha venido a instalarse sobre el llamado mundo de la vida, destruyendo en gran medida la experiencia social de muchos contextos locales.

En pocas décadas, los contextos de la vida que han venido desarrollando durante los siglos preindustriales, han sido fragmentados por la irrupción de la máquina y del mercado, lo que ha producido una ausencia de reglas en los valores, de anarquía organizacional, de destrucción del territorio, que , posteriormente ha sido muy difícil de paliar. Así mismo el fordismo ha definido muchos contextos tradicionales de acuerdo a las exigencias de la racionalización que uniformaba las diferencias, y que impedía la reproducción de las formas de vida local de acuerdo a sus especificidades. (Rullani, 2000, p. 249)

Esta proximidad con el mundo vivido es la base de un conocimiento protagónico que funciona como aval del conocimiento, sienta las bases para un espíritu científico genuino, basado en la observación y vivencia de los hechos. La acción es para Ladrière, el lugar de la ontología subyacente, en la interacción con el contexto, el cuerpo va formando y madurando las representaciones que la rigen y puede construir aproximaciones significativas, allí donde el conocimiento no puede aún establecer modelos (Ladrière, 1978, p. 41). Se vuelve vital en procesos que involucran decisiones con compromisos a futuro, en condiciones de incertidumbre (o donde el contexto social opera con certidumbres basadas en creencias consolidadas que impiden el pensamiento divergente).

Precisamente, la palabra modelo evoca dos nociones contradictorias, en una unidad inseparable: es un existente singular y, al mismo tiempo, una "plantilla ideal" para la producción de copias (es decir, una fuente de creación de elementos de un conjunto universal predeterminado). (Samaja, 2004, p. 27) 
Guiada por la precomprensión, modelizante, pone las bases para la construcción gradual y simultanea de la teoría y de la base empírica, en el sentido de que cada avance en operaciones en técnicas de observación ( metodología), alienta avances en operaciones de conceptualización. (Samaja, 2004, p. 29)

Y concluye que:

El objeto modelo de una investigación científica, no queda adecuadamente definido, si no a través de la descripción de al menos tres conjuntos de entes de distinto tipo, cuyos elementos mantienen entre si relaciones de sistema y subsistema, o de encajameinto. (Samaja, 2004, p. 32)

El objeto modelo, basado en la precomprensión modelizante, abre las puertas a la epigé- nesis (o génesis escalonada) "que va del caso análogo al caso presunto ( a modo de pre objeto modelo), y de allí, a la construcción de un objeto modelo como medidor entre el desarrollo de las reglas de Teoría y de Patrones de Observación”. (Samaja, 2004, pp. 27-28)

La transferencia de diseño

Todo proceso de aprendizaje se abre al detectar una anomalía en una práctica establecida. De allí la importancia de un conocimiento en la acción, que precede a la construcción del objeto de conocimiento. La acción, seguida de una anomalía, de una situación imprevista, desencadena el acto de aprendizaje. Ladrière (1978, p. 13) plantea como la cultura técnica mundializada, y representada en los ámbitos de la ciencia y de la tecnología, presionan sobre las culturas locales, y las desestructuran, proceso que implica una posterior restructuración con nuevas informaciones. Estas micro-situacións se producen en el marco de una gran rampa de aprendizaje que tiene al cambio tecnológico como proceso subyacente. El carácter intrínsecamente cultural de la propia ciencia y de la tecnología, carácter que la sociedad contemporánea niega al colocar a la técnica en el lugar de una supuesta neutralidad.

Intentamos poner el acento, de modo particular, por lo que se refiere a las culturas, sobre su dimensión ética (que forma parte del componente normativo de una cultura) y sobre su dimensión estética (que forma parte del componente expresivo de una cultura). Dos dimensiones especialmente significativas, porque pertenecen a las regiones más profundas de un sistema cultural: la ética está en la base de justificación y por esto regula en definitiva las conductas concretas y sus finalidades, y la estética constituye el lugar de la aparición de las disposiciones afectivas más significativas, que determinan e última instancia, el perfil concreto de la cultura. (Ladrière, 1978, p. 17)

El diseño tiene en sus objetivos, introducir a las unidades productivas, a los sujetos, a las comunidades de creación, al ambiente cultural de esta nueva macro semiótica, entendido como universo de sentido en el que se desarrolla la vida cotidiana contemporánea.

Este conocimiento es estratégico en la explotación del conocimiento codificado de la ciencia. La afirmación de Rullani (2000, p. 243) de que "el conocimiento surge en los contextos ya a ellos retorna", significa que el ciclo de producción de conocimientos se abre con la detección de una anomalía, en el desarrollo de una práctica en un contexto específico, protagonizada por algún actor de la comunidad, y se cierra cuando el problema se considera superado. Generalmente, se ha alcanzado este estado, si el nuevo conocimiento ha sido asumido, 
interiorizado e institucionalizado. En este arco intelectual, el conocimiento se presenta como conocimiento tácito, es codificado, combinado e interiorizado nuevamente (Nonaka, 1999, p. 81). A partir de este modelo destacamos el rol del conocimiento proyectual, en las fases de socialización e internalización, y que podemos considerar que una experiencia de transferencia, se inicia en un proceso de socialización, transita por un proceso de codificación/combinación, y cierra con la institucionalización de los aprendizajes. Si no completa el ciclo se trata de una experiencia exploratoria e incompleta.

En la quiebra a que nos expone el cambio tecnológico, se abre una efímera oportunidad de visualizar el carácter relativo y cultural del concepto de "racionalidad tecno-científica"; esta pequeña luz posibilitada por la fisura de un cambio estructural, hace de cada experiencia de vinculación una pequeña batalla por la libertad del espíritu, y nos devuelve una comprensión del campo disciplinar.

\section{La experiencia}

Puesto que nuestro objeto modelo expande las unidades de análisis al contexto, encontramos a los objetos anidando en la experiencia de transferencia de diseño que asumimos como nuestra unidad privilegiada. Asumimos esta definición que hace referencia a la necesidad de observar las anomalías en las prácticas de diseño.

Una experiencia científica es un procedimiento que consiste en hacer aparecer un efecto determinado , detectable y analizable, en circunstancias que han sido preparadas según un plan preciso, y en función de ciertas hipótesis relativas a los posibles efectos....

La idea de experiencia suele ir asociada con una alteración introducida de forma controlada en un sistema...y en consecuencia se opone la experiencia a la simple observación (donde no se da perturbación alguna en el sistema estudiado). Pero la caracterización que acabamos de hacer de la experiencia vale también para la observación. Observar científicamente un sistema no es anotar de modo pasivo lo que sucede en él, sino preparar un dispositivo con el que sea posible recoger las informaciones de una especie, elegida a sabiendas, que proceda del sistema. (Ladrière, 1978, p. 33)

El modelo actancial

Las prácticas de diseño se analizan en el marco de una matriz conceptual: el desarrollo como proceso que guía la programación de la acción. Proponemos la reconstrucción de las experiencias, a través del modelo actancial de Greimas (1987, p. 263). Samaja le atribuye un instrumento de construcción de la subjetividad, y al que propone como modelo universal de la acción humana mediada por objetos (Samaja, 2000, p. 127). El proyecto expresa las tensiones, entre un sujeto y un objeto representado por la satisfacción del deseo, en la superación de un conflicto que enfrenta factores adversos u oponentes, apoyándose en otros favorables o coadyuvantes a la satisfacción del deseo. Lo hace a través de una acción que supone un destinador, como legitimador y un beneficiario de la acción. El sujeto es el gerente que asume la conflictividad y coloca una meta superadora. El sujeto, en el contexto de éste artículo, es el investigador como depositario de una solidaridad sistémica, de una responsabilidad social, en el lugar del conocimiento, de la sociedad, enfrentado al objeto de deseo: la sustentabilidad. 
En todas las experiencias que hemos transitado, se enfrenta al sistema construido sobre la lógica del mercado como destinador y otra alternativa reclamando condiciones cognitiva, social y biológicamente compatibles con nueva s formas de subjetividad. El destinador está representado por una conciencia global emergente, construida sobre nuevas legalidades, pactos y compromisos que se van suscribiendo y van delineando nuevas formas de subjetividades, de objetividades, y de nuevos sentidos de comunidad. Los sujetos gerentes de este cambio, s e presentan como la universidad, las empresas, las organizaciones de la sociedad civil, construyendo laboratorios de sustentabilidad. Este destinador que representa a la ética de la responsabilidad, busca caminos para la reproducción de la vida, y no meramente del sistema, generando dinámicas y núcleos portadores de una sabiduría emergente. Si la sustentabilidad es el objeto de deseo, el miedo a las catástrofes, instala el sentimiento de responsabilidad social, ya sea Responsabilidad Social Universitaria, Empresaria, o de Colectivos Sociales.

La responsabilidad social, el comercio justo, la equidad de género, los derechos humanos, el diseño para todos, son posicionamientos éticos que derivan en nuevos modelos de gestión. La construcción de la sustentabilidad se asume también como una opción positiva, como una poética de la acción. La estética, ya no consiste en reproducir la realidad en otro soporte, si no en transformarla, a través de la acción planificada que percibe la reconstrucción del sentido de la vida.

Durante los últimos años hemos asistido a la apreciación de un nuevo sentimiento: el ecológico, y ello nos permite comprender mejor los mecanismos de la creación de un sentimiento. En el se trenzan muchos elementos de variada procedencia: datos y valores, miedos y esperanzas, ética y estética, cálculo y generosidad, sentimientos primarios y sentimientos sofisticados. (Marina, 2007, p. 146)

El modelo actancial expresa las tensiones de la acción a nivel de superficie, tal como lo experimenta el sujeto de proyecto. Las actividades de investigación acción necesariamente, entablan un diálogo entre las estructuras de superficie de las acciones, y las profundas de la significación. Esta coherencia surge desde una reconstrucción profunda de la experiencia social. Lo que subyace a estas acciones de superficie nos conecta con la experiencia jurídica, de formación de las normas y de las reglas, experiencias que deben ser evocadas para alcanzar éste objetivo.

El diseño entre la ciencia y el mundo de la vida

Para Samaja (2004) e Ynoub ( 2010) cada etapa del desarrollo epigenético ha creado sus específicas formas de subjetividad, con sentimientos que operan como disparadores de la acción transformadora (Samaja, 2004, p. 67). Cada etapa se construyó a partir de una incesante búsqueda de libertad, superando y suprimiendo las etapas anteriores y a partir de restricciones al desarrollo de la vida social. El sentimiento que impone la globalización, es el de la marginación/exclusión que hemos descripto en todos varios matices. Estas experiencias nos muestran que se están delineando nuevas formas de subjetividad. El énfasis en la subjetividad, revierte la reflexión sobre el diseño como sistema proyectual de las comunidades y de las organizaciones, como interfase entre el mundo de la vida y el conocimiento codificado. Christensen (Christensen, 1999, p. 20) pone de manifiesto las dificultades para comprender las innovaciones abruptas ocasionadas por el cambio tecnológico, apuntando que en la mayoría de los casos, luchamos en contra de los procesos de cambio. "Como muchas de las cuestiones más estimulantes de la vida, tiene gran valor tomar en cuenta 'la manera en que funciona el 
mundo' y administrar los esfuerzos innovadores de forma tales que puedan adecuarse a dichas fuerzas". (Christensen, 1999, p. 20)

Se atribuye la causa al carácter sistémico de los sistemas técnicos, y a la adopción de un marco de referencia restringido en la apreciación de los errores, entre otros.

El desarrollo de la ciencia y de la tecnología, que dio lugar al fordismo, generó conocimientos estructurados, que vinieron a establecerse por doquier, destruyendo por así decir, el mundo de la vida (Rullani, 2000, p. 249)19. Los campos de convergencia que han cobrado relevancia en los escenarios del campo proyectual son la nueva concepción de patrimonio, la economía ecológica, las llamadas tecnologías sociales y el concepto de diseño saludable Todas estas perspectivas enfrentan la mercantilización de los recursos culturales, naturales, humanos y culturales, y su reducción a su condición de capitales de la economía globalizada, imponiendo un nuevo marco ético a la actividad proyectual.

Podemos establecer que los subsistemas socio técnicos han entrado en contradicción con las dimensiones ecológica políticas y bio-comunales. Las primeras reclamando equidad y diversidad, las segundas una acción respetuosa de los recursos naturales y en estas tensiones, se encuadran las dinámicas proyectuales contemporáneas. Una de las tomas de conciencia reflejan el hecho de que las soluciones de la modernidad, sobre las cuales se construyó la cultura material del siglo XX, no son escalables, han mostrado sus límites en relación a la escala de las necesidades planetarias, en particular a los 4 billones de personas desatendidas por la economía, cifra que Prahalad (2010) ha puesto en el centro de la reflexión del diseño y de la economía. (2010, pp. $4-5) 20$

De Sousa Santos (2008, p. 86), señala como camino la construcción de una axiología del cuidado, por oposición a una de acumulación. Llama una sociología de las ausencias, que han permitido que predominen los efectos reguladores del conocimiento estructurado en detrimento de los emergentes. Esta sociología de las ausencias, ha tenido en las actividades productivas, un impacto considerable, al hacer predominar los patrones asociados a la transferencia de tecnologías exógenas, por sobre las prácticas locales (2008, p. 88). El desarrollo endógeno supone una reingeniería del conocimiento reordenando, re direccionando y subordinando los recursos bajo el control de los valores.

Metodología de las investigaciones acciones

Las investigaciones acciones corresponden al tipo de investigaciones tecnológicas, cuyo objeto es validar cursos de acción o modelos de gestión y cuya eficacia es sociotécnica (Samaja, 2004, p. 58). Obsérvese sin embargo que las acciones de transformación afectando objetos, anidan en proceso de formación de la subjetividad y afectan a la comunidad en la medida en que crean nuevas reglas. El proceso culmina con la codificación del conocimiento y con su institucionalización.

Si entendemos al diseño como conjunto de prácticas de planificación, y a la práctica como la implementación de reglas (Samaja, 2004, p. 204)21, la actividad investigación acción se despliega para revisar activamente las reglas y categorías sobre a las que están construidas. Las totalidades estructuradas según reglas comparten una misma zona epistemológica en que la relación entre sujeto y objeto, implica una relación de imputación validada por un sistema. Por lo tanto, el dispositivo de investigación acción saca a luz las reglas y su sentido, 
reconstruyen el momento original en que tales relaciones de sentido fueron establecidas y validadas. Es lo que llamamos contextualización, por que evoca la totalidad, como el límite de validez de la regla. Hasta que esos componentes están juntos, no hay semiosis, en esto radica el valor de conocimiento de esta operación, la posibilidad de entablar una relación entre la regla y el sentido común.

Acción y significado

Consideramos como marco de referencia la construcción de una semiótica de la acción, que se constituye entre el sujeto trascendente y el sujeto práctico (Samaja, 2000, p. 72) con un interés doblemente específico:

1. Considera a la acción como base del sentido.

2. Desarrolla formalismos para describir las estructuras que organizan la génesis del sentido (Samaja, 2000, p. 79)22. La acción se hace semiosis en la medida en que cohagula como configuraciones estables o prácticas, de carácter recurrente y rutinario, sometidos sin embargo a procesos de reproducción recursiva (Samaja, 2004, p. 78)23. Esto supone explicar los procesos de gestión en términos de narrativas. La narración tiene un efecto de restitución del sentido. Pero como la acción implica cambios o transformaciones de estado, las intervenciones, como unidades de análisis se expresan como enunciados de hacer y enunciados de ser. Las intervenciones o acciones, tienen estos dos componentes, uno descriptivo, que expresa el estado, y uno de transformación.

En la estructura dramática identificamos los siguientes elementos:

- Una totalidad contextual como comunidad regulada de partes.

- Las acciones cíclicas

- Sujetos biográficos

- Situaciones

- Cambios en las situaciones

- Revelación de aspectos nuevos en la situaciones

- Revelación de aspectos nuevos en los sujetos

- Nuevas vivencias y acciones

- Experiencias históricas.

Los tipos de unidades de análisis involucrados en un proceso narrativo:

- Un acto elemental (gestión, decisión de diseño), que transforma un estado en otro.

- La acción como encadenamiento de actos que reunidos pueden atender a un fin culturalmente reconocible. 
- Ciclos de acciones como reiteración periódica de las acciones

- Pautas de ciclos de acción, conjuntos de ciclos de acción con coherencia estructural

- Cambios de pautas de ciclos de acción, alteración o reconfiguración de la situación

- Pauta de cambio de pautas, ciclo de desarrollo

- Acontecimientos, conjuntos de acción que interfieren las pautas de los ciclos de acción, ya sea inesperados o esperados. (Samaja, 2000, p. 190)

El modelo como artefacto cognitivo

El modelo se hace presente en la práctica de transferencia de diseño mediante un documento de registro, que es un disparador de la reflexión y que en si mismo propone una ontología de la gestión de diseño para repensar su práctica. En éste documento, aparece representado en un modelo matriz, las diferentes entidades involucradas en la práctica y susceptibles de ser gestionadas. Esta visualización de la realidad en estratos, relacionados orgánicamente, ayuda a visualizar a la gestión del producto, con un contexto subunitario de componentes o subsistemas, y en sentido ascendente, los contextos relevantes, entificados como sistema de comunicación, como familia de productos, como colección, como oferta de productos, como unidad productiva, como circuito comercial, etc.. Esto introduce una mirada a partir de un "lente zoom", sobre la propia práctica, y sus contextos entificados, tal como se presentan, y se comienza trabajar sobre el recorte y los puntos problemáticos. El hecho de que el modelo se presente vacío de datos, implica que puede ser llenado con opciones y valores para las variables de cada nivel actuando las variables como conmutadoras semánticas entre lo existente, lo deseable y lo posible. Lo posible, es el compromiso entre lo existente, lo deseable y las totalidades regulantes del contexto de la acción. Se pueden percibir las consecuencias contextuales de las decisiones. El modelo permite la especulación entre lo presente existente y lo futuro deseable. Instala un vocabulario para designar los entes y las operaciones. Como toda ontología, tiene un efecto de ocultamiento sobre lo que no designa, y de revelación sobre lo incluido, pero de hecho, representa un avance sobre la representación tácita.

Cuando el objeto es la gestión de diseño, la unidad de análisis es el acto de intervención sobre el objeto modelo construido, que describimos como un tipo de operación de transformación que implica un hacer ser. Es una decisión de proyecto, que trae aparejadas transformaciones simultáneas en el objeto en su dimensión relativa a un sujeto que le asigna sentido. En todos las entidades hay un sujeto objeto que va siendo modificado por la gestión. La sensibilidad al contexto, es la presión que ejercen las unidades entre sí, las superiores en relación a las contiguas inferiores. La negación o afirmación de la operación tienen consecuencias sobre las totalidades regulantes y las unidades contiguas y obligará a un reajuste de partes, a otras intervenciones en el mismo o en otros niveles de organización de las totalidades estructuradas sobre las que se opera.

Las acciones de transformación pueden involucrar a un nivel o varios, dependiendo de la amplitud de la reestructuración requerida para lograr la estabilidad. Puede tratarse de una acción requerida o de un estilo de gestión, basado en la fijación de metas. Como lo hemos señalado, estas acciones no están regidas solo por obstáculos sino también desencadenadas por la existencia de oportunidades en el entorno. 
En un ejercicio pedagógico confrontamos lógicas de gestión proyectual de diseñadores y artesanos en relación a una organización de pequeños productores, percibiendo que los diseñadores seguían un criterio de maximización de las posibilidades de ocupación de nichos de mercado, con una gestión invasiva a todos los niveles de la gestión. Mientras los artesanos, actuaban con un criterio más conservador, en la medida en que privilegiaban la calidad de vida que relacionaban a la permanencia en el territorio, que contradecía la puesta en marcha de un proyecto expansivo. El modelo muestra la lógica expansiva del diseño en relación con la lógica conservadora de los artesanos. La comprobación era que los objetos anidan en universos de valor y que las instituciones ajustan su comportamiento al sostén de tales valores.

El diseñador construye una representación de tipo jerárquico y organísmico, del tipo que hemos descripto, define la amplitud de la observación, construye las unidades de análisis, y detecta las relaciones recíprocas entre partes. Delimita una zona de gestión, de otra, que está fuera de su alcance, la cual construye como contexto. En una gestión a escala de unidad productiva, las entidades observadas son la unidad productiva, sus escenarios relevantes, su sistema de comunicación, su gestión a nivel político, su oferta de productos, sus colecciones, sus productos en particular, sus componentes constitutivos que revelan sus insumos, materiales, proveedores y procesos. En un director de proyecto, esta matriz se amplía hasta la observación de las dinámicas de actores productivos en diversas escalas territoriales. Lo que llamo un "lente de zoom" sobre una realidad y un entorno más complejo y extenso. El investigador actor se desplaza en el marco de esta representación, desplazando su atención o concentrándola en diferentes niveles o entidades. Los niveles de la totalidad estructurada están entificados, por lo que se puede hablar de gestión a escala de producto, de componente, de sistema, de oferta, de unidad productiva, etc. Si en la gestión, la mente se desplaza, incluso, sobre diferentes construcciones del escenario, (productivo, comercial, político, etc.), en la investigación, es necesario clausurar, limitando la entidad sobre la que se actuará, posicionándola como nivel focal, y construir al menos un contexto relevante supra unitario y otro infra unitario en los que a su vez se seleccionaran solo las variables puestas en juego. Esto, se hace después de establecer una dirección de análisis, y seleccionar en las entidades de contexto representativas par esa dirección de análisis. Luego el modelo es compactado, y permite diversas construcciones: tipologías en el sentido de la variable, puede sustentar una actividad hermenéutica de los datos.

Este desplazamiento de la mente del diseñador contextualizando su objeto de diferentes maneras, es un ejercicio natural de las tensiones entre lo micro y lo macro. El producto es el reflejo del contexto de sus condicionamientos y oportunidades, y habla acerca de las condiciones de su gestación. El diseño incorpora el enfoque eco sistémico, que se posiciona en la visión de la reproducción de la vida y parte de un equilibrio entendido sistémicamente. Es un posicionamiento ético y también estético en la medida que pensamos la estética como la coherencia de las praxis, que privilegian la estabilidad y la reproducción del sistema como una dinámica parte-todo.

La tensión entre parte y todo, es el lugar del sujeto, y su transición, la emergencia de una conciencia de pertenencia, es su momento constitutivo. La presencia regulante de un todo en la parte desarrolla la sensibilidad al contexto como fundamento de las conductas funcionales. Es el lugar del sentido de comunidad y pertenencia y del sentido de complementariedad y de su resolución depende la sustentabilidad. Samaja atribuye una 
relevancia particular a ese preseverar en el origen como lugar del sentido, es la identidad que significa reconocerse en la misma entidad.

"Toda estructura perseverante, es siempre una historia viviente que retorna a un sistema de límites, pero precisamente, por esa propensión al retorno se desarrolla y se transforma”. (Samaja, 2004, p. 156)

La lectura de escenarios, consiste en la construcción de un horizonte problemático sobre el cual se interpreta la singularidad del acontecimiento, de la intervención, cuya significación se construye conjuntamente con el escenario en el mismo acto interpretativo. Los escenarios son totalidades representacionales, a los cuales deben adecuarse las conductas de los agentes, de los productos desde una lógica funcional. Cuando reconocemos una singularidad, (producto, acontecimiento, comportamiento, intervención), y la contrastamos con las lógicas y dinámicas de cada escenario estamos reconstruyendo en forma ascendente, el proceso de formación de concepto o categorías, como dinámica entre lo individual (el caso, la ocurrencia), lo particular (el tipo de comportamiento definido por una rasgo), y lo universal (el escenario como el universo de los posibles). Samaja llama clínica a la estructura que reconstruye los objetos de cada disciplina en un proceso sistémico de estas características.

Efectivamente, lo que construimos como escenarios o narrativas de desarrollo en las experiencias de transferencia, consiste en contextos problemáticos que se construyen para interpretar el sentido de la intervención de diseño. El reconocimiento de tales escenarios, problemática y gestiones se hacen desde la disciplina, se reconocen desde la práctica, pero se exploran desde la investigación-acción.

La construcción de la sustentabilidad

En este enfoque el objetivo del proyecto es la creación de la sustentabilidad. Los múltiples matices del concepto se pueden resumir de un conjunto de compromisos suscriptos, a modo de pactos preexistentes, que representan los marcos a los que debe inscribirse toda acción. Este nuevo marco ético reinterpreta las necesidades en términos universales, pero que a su vez deben ser reinterpretadas en la esfera de las comunidades locales, problematizadas localmente, transformadas en políticas y posteriormente, apropiadas reinterpretadas y actuadas en el ámbito de la vida real y cotidiana de los individuos, y este es el tema del diseño. Este cambio de enfoque requiere del desarrollo del sentido de comunidad como base de la sustentabilidad a través de perseverar en el origen y reconstruir ese límite. Este sentido común es un emergente de la vida social y se expresa como una función redistributiva, podríamos decir, inclusiva.

El escenario de la globalización, impone nuevas condiciones al desenvolvimiento social, en el cual un grupo de actores, universidad, asociaciones libres, empresas establecen vínculos y acuerdos para asegurar la reproducción de la vida, establece pactos que expresan una solidaridad planetaria, pero construidos localmente, establecen un ética de la responsabilidad proponiendo un campo semántico -sustentable/no sustentableinstalan la ecología como competencia semiótica, que establece la responsabilidad social como sentimiento ético, y se reproduce a través de la ecología de la acción (Vallaeys, 2011). Esta, la ecología de la acción, piensa a la sociedad como un todo, es poética, en la medida en que su objetivo es restaurar una coherencia de praxis entre sujetos y ambientes y es ética de tercera generación, porque responde a un proyecto de solidaridad sistémica. El disvalor negativo es la muerte, el riesgo de catástrofes, la culpa de dejar un planeta agotado. Desde el campo del proyecto, la sustentabilidad, se constituye de muchas islas de sustentabilidad, a modo de 
micro escenarios en los lugares en que el sujeto puede autoafirmarse y desarrollar sus ámbitos de coherencias. La zona del conocimiento proyectual es construir la sustentabilidad en la esfera de lo personal cotidiano y de lo local comunitario. El sujeto de conocimiento como sujeto histórico está ante la alternativa de recrear la ética como solidaridad sistémica universal, "una ética Universal” , ...como "la más deslumbrante creación de la inteligencia humana". (Marina, 2000, p. 255)

Apel en su libro La globalización y una ética de la responsabilidad, menciona la capacidad de la ciencia para generar poder simbólico, construyendo el discurso argumentativo a través de una ética de la responsabilidad.

El desafío externo radica reside manifiestamente en las consecuencias técnico prácticas de la ciencia para la vida de la moderna sociedad industrial, inclusive hasta la crisis energético nuclear y ecológica. Este desafío externo hace que por primera vez en la historia de la humanidad a esta se le aparezca como algo urgente algo así como una macroética de la responsabilidad solidaria, de extensión planetaria. (2007, p. 172)

Apel propone una pragmática trascendental, para validar el discurso científico sobre el consenso de la comunidad de intérpretes, rechazando el rigorismo del imperativo categórico y reconociendo la necesidad de una solidaridad pos convencional, que se hace cargo de la situación del estado de naturaleza, aun no constituido como convención, de éste conjunto de compromisos que se sintetizan en la ética de la responsabilidad. Se refiere al carácter minimalista de esta ética universal y a sus condiciones de existencia para no caer en un enfoque dependiente. (2007, p. 173)

El sentimiento ético es la responsabilidad social, como "la capacidad de dar respuesta a la sociedad como un todo" (Vallaeys, 2008). Tal como se ha señalado, la RS no tiene un teórico ni un libro referente, si no que es un movimiento polimorfo que representa una nueva forma de subjetividad emergente en todo el espectro institucional, de signo local, pero que se presenta como una realidad global. De hecho, la RS se presenta como un conjunto de buenas prácticas de gestión cumpliendo con un importante conjunto de compromisos internacionales. La RS no es un movimiento de solidaridad social simplemente, ni un movimiento político, se la intenta proteger de la manipulación del marketing político a través de la existencia de indicadores efectivos.

Transferencia y legalidad

La actividad instituyente de la transferencia de diseño pone a los marcos académicos jurídicos a la confrontación con los procesos sociales de reconstrucción de las prácticas productivas. Dice Bachelard

Cualquier cultura científica debe comenzar, como detalladamente, por una cierta catarsis intelectual y afectiva. Queda entonces la tarea más difícil: poner la cultura científica en estado de movilización permanente, sustituir el saber cerrado y estático por un conocimiento abierto y dinámico, dialectizar todas las variables experimentales, dar finalmente a la razón motivos para que evoluciones. (Bachelard, 1974, p. 192)

Morin sostiene que cuando los marcos académico-políticos no reflejan el mundo de la vida, las actividades que crecen al margen, como externalidades terminan siendo funcionales al orden jurídico en crisis, porque permiten que el sentido común se desarrolle y equilibre la ausencia de sentido en las reglas. Un criterio legalista de carácter rigorista suele interrumpir los flujos. Pero la postergación de la discusión académica puede ser aprovechada por las prácticas especulativas y poco transparentes. Por lo tanto, existen momentos particulares, 
foros de discusión y lugares para llevar ésta discusión a los términos esperables, que generen el máximo aprovechamiento de las externalidades institucionales para alimentar la autorreflexión. Todas las instituciones inteligentes pueden revisar sus regímenes de funcionamiento para dar respuesta los contextos de la acción. Es necesario posicionarse en el lugar del sentido, no meramente de las reglas (Morin, 2007, p. 129). Para Morin "la solidaridad vivida es lo único que permite el incremento de la complejidad". (2007, p. 130)

A modo de conclusión : el obstáculo removido

La formación de sujetos epistémicos, capaces de construir modelos, de alcanzar la abstracción, es condición para el desarrollo disciplinar. Si las profesiones del diseño, son culturas de la acción, una reserva de conocimientos tácitos y explícitos capaz de ser evocadas, por profesionales autónomos, también es cierto que estos profesionales están habilitados por un siglo de pensamiento de diseño, recursos conceptuales, teóricos y metodológicos. Si los diseños son una reserva de conocimiento, un patrimonio de los países, las regiones, las organizaciones para enfrentar contingencias, necesitan de un capital científico, que se desarrolla a través posgrados y doctorados, para poder enfrentar las complejidades de la ampliación de sus campos. Si los diseños pueden hoy desenvolverse en los campos emergentes de los medios, de la producción flexible, de la economía solidaria, de competencia o en ámbitos públicos como gestor de políticas, con ventajas en relación a disciplinas nuevas, es porque cuentan con ese patrimonio de recursos y una historia que los habilita. Este patrimonio de saber se hace presente cada vez que un diseñador, donde quiera que se desempeñe, pero sobre todo en campos emergentes, enfrenta a un proveedor, a un operador, a un ministro, a un empresario, y a profesionales de otras disciplinas.

Con respecto al objeto, La consideración de los procesos, nos devuelven una visión más compleja: como artefactos, hechos conforme a reglas, como dispositivos, en el momento de la interacción, como objeto-modelo, en una instancia abstracta y ontológica, y como productos cuando alcanzan la institucionalización. (Samaja, 2016)

Notas

1. En nuestro modelo, el diseño es un proceso de reducción progresiva de incertidumbre (Lebahar, 1993), a través de un proceso de equilibración entre estas tres formas de representación, que el diseñador involucra en sus dinámicas productivas. El concepto es lo que designamos como hipótesis, el esquema es el partido, como representación topológica y la imagen, la apariencia del producto que valoriza la subjetividad. Los sistemas gráficos, entendidos como instrumentos del proceso constructivo, son trazas de estas representaciones mentales e interfases con la realidad material. De allí, que este modelo propone una clasificación de los sistemas gráficos en relación al contenido de incertidumbre que pueden absorber, desde los puramente topológicos, sin métrica, y personalizados, adaptándose al elevado contenido de incertidumbre de las primeras representaciones mentales del proceso, hasta los más altamente formalizados y socializados, para comunicar la solución en sus fases finales de resolución y producción. Galán, B., Poy M., El desarrollo de la visión sistémica en la formación del diseñador, Centro CAO, FADU, UBA, 1994.

2. Galan, B.; Orsi, L., 2009.

3. Red (IA), Proyectos de las Programaciones Científicas 2004-2007, 2007-2011, 11-14 y 1417. 
4. Centro de Investigación en Proyecto, Diseño y Desarrollo, SI-FADU, UBA. Creado en el 2012 por Res. CD $78 / 12$.

5. Camillioni, A., 2010, Curso de Didáctica general, Doctorado FADU-UBA.

6. Margolin habla de Diseño para el Desarrollo, como una invitación a repensar las capacidades del diseño para enfrentar los problemas del desarrollo humano, en Design for development: towards a story, Design Studies 28, 2007. Oosterlaken, dice que si bien, esta expresión estaba asociada la pobreza y la periferia , devino progresivamente en lo que el llama capability approach, inspirada en los escritos de Amartya Sen, y Martha Nussbaun, (p. 19) y en la introducción del concepto de dignidad humana y derechos humanos en el campo del diseño, sugerido por Buchanan Massachusetts Institute of Technology, Design Issues: Volume 25, Number 4 Autumn 2009. Buchanan en Human Dignity and Human right, Thougt in principles of human centered deisgn. Design Issues: Volume 17, Number 3 Summer 2001.

\section{Primeras Jornadas de Diseño y Comunicación para el Desarrollo Local, FADU - UBA, mayo Del 2006,} Segundas Jornadas de Diseño para el Desarrollo, Universidad Nacional de Córdoba, mayo del 2008. Terceras Jornadas de Diseño para el desarrollo, Universidad Nacional de Cuyo, nov. Del 2010 y 2008 y cuartas Jornadas latinoamericanas de Diseño para el Desarrollo local, mayo del 2011, Universidad nacional de san Juan.

8. Ledesma, M., Conferencia en las Jornadas de Investigación de la Facultad de Arquitectura, Diseño y Urbanismo, Universidad de Buenos Aires, 2009. Foro de Innovación de las Américas, LATU, Montevideo, 2011. http://www.fia.uy

9. “El término -epigénesis- procede de la embriología. Y se aplicó para hacer referencia a los procesos de desarrollo por estadíos, en el que cada estadío nuevo se construye sobre los estadíos anteriores. En este ensayo, el término epigénesis puede traducirse como "génesis a partir de un statu quo ante)" (Cfr. Bateson 1980, p. 201). Samaja, 2004, 136.

10. “...una pedagogía de lo previsible y el orden, pero también del devenir y el caos. En última instancia, una pedagogía que se involucre con los social y sepa sostenerse sobre las turbulencias, antes que aspirar a pedestales inmóviles o verdades universales. Se trata, en definitiva, de una pedagogía del sentido", se aclara que el sentido se entiende como lo que deviene. (Diaz, Ester, 2007, p.78)

11. United Nation Environmente Programme, Design for sustainability: a steep-by-steep approach. UNEP, 2009.

12. "La mayor parte de estos modelos, que nos sirven para inventar cosas, entre ellas proyectos, son aprendidos. Una cultura es, entre otras cosas, un repertorio de proyectos, elaborados por sus miembros a lo largo de la historia". Marina, 2010.

13. Para Peirce: a) Primeridad "es el modo de ser de aquello que es tal como es, de manera positiva y sin referencia a ninguna cosa. (Peirce, 1974, p. 86) b) Segundidad "es el modo de hacer de aquello que es tal como es, con respecto a una segunda cosa, pero con exclusión de toda tercera cosa". c) Teceridad "es el modo de ser de aquello que es tal como es, al relacionar una segunda cosa y una tercera cosa entre si". (Peirce, 1974, p. 86) 
14. Samaja, J., Semiótica y dialéctica, seguido de la lógica breve de Hegel, Episteme, JVE Ediciones, Buenos Aires, 2000, p. 14.

15. Samaja atribuye a Kant el haber "agrupado las categorías para determinar las relaciones en tres grandes especies: i) relaciones de cosa o propiedad (sustancia/accidente), ii) relaciones de procesos (casusa efecto), iii) relaciones de funcionalidad (causación recíproca o comunidad). (Samaja, 2004, p. 64)

16. “Como sujeto de un a cierta alianza, y por ende, como sujeto carente y simbólicamente completado por un "pacto de unión con los otros"'. (Samaja, 2004, p. 96)

17. Samaja, 2004.

18. Merleau-Ponty, Fenomenología de la percepción. (FCE p. VII), citado por Samaja (2004, p. 20)

19. "En pocas décadas, los contextos de la vida que han venido desarrollando durante los siglos preindustriales, han sido fragmentados por la irrupción de la máquina y del mercado, lo que ha producido una ausencia de reglas en los valores, de anarquía organizacional, de destrucción del territorio, que , posteriormente ha sido muy difícil de paliar. Así mismo el fordismo ha definido muchos contextos tradicionales de acuerdo a las exigencias de la racionalización que uniformaba las diferencias, y que impedía la reproducción de las formas de vida local de acuerdo a sus especificidades" (Rullani, 2000, p. 249). "Se hace necesario reestructurar el conocimiento, relacionándolo con el mundo de la vida, lo que se da en dos instancias: en la detección de las anomalías de las prácticas sociales (de tácito a explícito) y del conocimiento codificado a su apropiación en la trama de la vida (de explícito a tácito).

20. Lo caracteriza como un vasto sector no homogéneo, para cuya descripción no hay acuerdos generales, pero que se caracteriza por su exclusión total o parcial de los circuitos del consumo. En este sector Prahalad distingue los sectores de la extrema pobreza, ganando menos de $\$ 2$ diarios, de sectores con ingresos de $\$ 4$ diarios, mercados emergentes, y sectores de extrema pobreza que no pueden constituirse como micro productores o micro consumidores y para los cuales, la asistencia estatal debe atender hasta el momento en que puedan escapar de ésta condición. (Prahalad, 2010, pp. 4-5)

21. "La existencia de una regla solo se comprende por referencia a una totalidad que existe gracias al cumplimiento de las acciones prescriptas a sus partes por la regla". (Samaja, 2004, p. 205)

22. Con énfasis en los contextos del mundo natural, y en los contextos comunitarios de donde emergen las lenguas naturales, y entendiendo el sentido común como un "universo de percepciones dotadas de sentido", que enmarcan en la polaridad entre objeto y sujeto, tiene implicancias en una teoría del conocimiento.

23. Samaja sugiere que mediante la acción el mundo vivido puede recrearse como lengua, porque está en el origen de ambas, del discurso científico y del natural. Todo ser semiótico es ante todo un ser viviente. Se postula que los sistemas semióticos son abiertos a la realidad, a la acción se le oponen las cosas mismas, los seres vivientes luchan en el mundo real, aunque deban referirse a sus experiencias vitales apelando a signos. 
Apel, K. O. (2007). La globalización y una ética de la responsabilidad. Buenos Aires: Prometeo.

Bachelard, G. (1981). La formación del espíritu científico. 9a edición. Siglo veintiuno editores.

Bachelard, G. (1971). Epistemología, Editorial Anagrama, Barcelona, 1874, Título de la Edición Original: Epistemology, Press Universitaires de France.

Badiou, A. (2009). El concepto de modelo, Introducción a una epistemología materialista de las matemáticas, La Bestia Equilatera, Buenos Aires.

Bateson, G. (1980). Espíritu y naturaleza. Buenos Aires: Amorrortu Editores. . (1998). Pasos para una ecología de la mente, Una aproximación revolucionaria a la autocomprensión del hombre. Buenos Aires: Ediciones Lohlè-Lumen.

Baquero, R. (2008). Camillioni, A.; Carretero, M.; Castorina, J. A.; Lenzi, A.; Litwin, E. Debates constructivistas. Buenos Aires: Aique.

Becattini, G y Rullani E. (1996). "Sistemas productivos locales y mercado global” en ICE: Información Comercial Española, Revista de Economía, No.754, junio, España.

Buchanan, R. (2001). Human Dignity and Human right, Thougt in principles of human centered deisgn. Design Issues: Volume 17, Number 3 Summer 2001.

Bernal. M. E. (2013). “Lo social también requiere innovación”. CEPAL. Foro de Innovación de las Américas. Montevideo. 2011. Disponible en: http://www.fia.uy. Entrada 10/5/2013.

Brook, P. (2011). "El nuevo mundo de la innovación. Desafíos y oportunidades para América Latina”. Foro de Innovación de las Américas. Montevideo. 2011. Disponible en: http://www.fia.uy. Entrada 10/5/2013

Becattini, G y Rullani, E. (1996). "Sistemas productivos locales y mercado global" en ICE: Información Comercial Española, Revista de Economía, No.754, junio, España.

Bernatene, M. Del R.; Galan, B. (2003). Nuevas redes sociales como objetos de deseo para el diseño, 2do Congresso Internacional de Pesquisa em Design, Rio de Janeiro, Brasil.

Boscherini, F. y Poma, L. (compiladores) (1992). Territorio, conocimiento y competitividad de las empresas. El rol de las instituciones en el espacio global. Madrid: Miño y Dávila Editores.

Cross, N.; Dorst, K. (eds) (1992). Research in design thinking, Delf University Press, Delft, The Netherland.

Camillioni, A. R. W. de (1997). Los osbtáculos epistemológicos en la enseñanza. Barcelona: Gedisa.

Christensen, C. (1997). El dilema de los innovadores, Cuando las nuevas tecnologías pueden hacer fracasar a las grandes empresas. Buenos Aires: Granica. 
Cross, N. (2001). Designerly ways of knowing: design discipline versus design science, Design Issues, Vol. 17, No. 3, pp. 49-55.

De Sousa Santos, B. (2008). Conocer desde el sur. Para una cultura política contemporánea, Editorial Universidad Bolivariana, Colección Nuevos Paradigmas, Santiago de Chile.

De La Cruz Ayuzo, C. y Sasia Santos, P. (2008). "IESALC, El movimiento de responsabilidad social de la universidad: una comprensión novedosa de la misión universitaria”, en Educación Superior y Sociedad, Nueva Época (Eve Vessuri, ed.). (Caracas: EES, año 13, №2).

Diaz, E. (2007). Entre la tecnociencia y el deseo, La construcción de una epistemología ampliada. Buenos Aires: Editorial Biblos, Filosofía.

. ( editora) (2012). El poder y la vida, modulaciones epistemológicas. Editorial Biblos.

Donald, A. N. (1988). La psicología de los objetos cotidianos, Título original: The psycology of everyday things. Basic Books, Editorial Nerea.

Elliot, J. (1991). "Estudio del currículum escolar a través de la investigación interna", en Revista Interuniversitaria de Formación del Profesorado, 10, pp. 45-68). Ver . . (1988). "What is reseach action in school?", en The Action Research reader (Australia: Deaking University Printery, Production Unit, pp. 121-122).

Elizalde, A.; Hopenhaimer, M.; Max-Neef, M. (1997). Eco-Economía y desarrollo. Buenos Aires: Ediciones de la Universidad.

Galan, B. (2008). El diseño en la agenda de la transferencia, el rol de la Universidad, presentada en las Primeras Jornadas de la Red de Vinculación tecnológica, RED VITEC, Paraná, del Consejo Interuniversitario Nacional, Paraná.

Galan, B.; Villasante, T. R.; Martín Juez, F.; Novik, L.; Blanch, A.; Rossi, A.; Naranjo, E.; Toquita Clavijo, M. (2007). Diseño \& territorio. Bogotá: Editor F. Díaz Granados, Fac. de Artes, Universidad Nacional de Colombia.

Galán, B. (2008). El rol del diseño en las economías creativas, Impacto Económico del Diseño en Argentina, ProDiseño, Instituto Nacional de Tecnología Industrial, http://www.inti.gov.ar/prodiseño/ie_anexo_galan.pdf.

. El diseño en la agenda de la transferencia, II Jornadas Red VITEC - La Vinculación Tecnológica en el contexto de las Políticas de Estado y la Sociedad, Entre Ríos, Paraná, 19 y 20 de Noviembre de 2008. http://www.redvitec.edu.ar/contenido/index.php? tid=120

Galan, B.; Orsi, L. (2009). La mirada del diseño entre el proceso y el proyecto: Implementación de una didáctica de la complejidad en la cátedra de Metodología aplicada al diseño, Jornadas de Investigación SI+DiPRO, Didáctica del Proyecto, Secretaría de Investigaciones, Buenos Aires, setiembre del 2009. (En prensa). 
Galan, B. (2011) (Comp). Diseño, proyecto y desarrollo. Miradas del período 2007-2010 en Argentina y Latinoamérica. Buenos Aires: Wolkowicz ediciones.

Galan, B. (2011). Proyecto y construcción de sentido en las prácticas académicas y en las gestiones sociales por diseño, Capítulos 1, 2 y 3, del libro: Diseño, Proyecto y Desarrollo, Galán, B. (compiladora). Buenos Aires: Editorial Wolkowicz.

Greimas, A. J.; Courtes, J. (1990). Semiótica, Diccionario razonado de la teoría del lenguaje, Biblioteca Románica Hispánica. Madrid: Editorial Greidos.

Galán, B.; Poy, M. (1994). Algunas aproximaciones teóricas y definiciones sobre el proceso de diseño (en colaboración), Primer Congreso Internacional de Matemática y Diseño, FADU, UBA. Expositor. 1995.

Greimas, A. J. (1987). Semántica Estructural, Investigación metodológica. Madrid: Editorial Gredos.

Greimas, A. J.; Courtes, J. (1986). Diccionario razonado de la teoría del lenguaje. Madrid: Editorial Gredos.

Heller, A. (1995). Una revisión de la teoría de las necesidades. Barcelona: Paidós.

Ladrière, J. (2001). El reto de la racionalidad, Buenos Aires: Sígueme.

Ledesma, M. (2007). Seminar: Didáctica del Proyecto (Project Didactics), Programa de Doctorado (Doctorate Program), FADU.

Ledesma. M. (2005). Sobre legitimidades y olvidos. Tesis Doctoral, Biblioteca de la Facultad de Arquitectura, Diseño y Urbanismo.

Lakatos, I. (2001). Simposio con la participación de H. Feigl, R. Hall, N. Koertge, T. Khun. Historia de la ciencia y sus reconstrucciones racionales. Madrid: Editorial Teknos. Manual De Bogotá, Normalización de Indicadores de Innovación Tecnológica en América latina y el Caribe, RICYT, OEA, CYTED, Marzo del 2001. http://www.ricyt.org/interior/difusion/pubs/bogota/bogota.pdf (Entrada 17 de abril del 2010).

Manzini, E. (2006). Creative communities, collaborative networks and distributed economies. Promising signals for a sustainable development. DIS. Indaco. Politecnico di Milano. Draft. Disponible en: http://www.sustainableeveryday.net/manzini/.

Marina, J. A. (1993). Teoría de la inteligencia creadora. Barcelona: Anagrama.

Creative communities, collaborative networks and distributed economies. Promising signals for a sustainable development, DIS. Indaco, Politécnico di Milano, Draft, 2006, http://www.sustainableeveryday.net/manzini/.

Manzini, en Paris, O. (director) (2005). 30-60, Arquitectura y Medio Ambiente, I, Cuaderno latinoamericano de Arquitectura, Córdoba, 2005. 
Margolin, V.; Margolin, S. (2002). "Social Model" of Design: Issues of practice and research, Design Issues, Massachussts Institute of technology, Volume 18, Number 4, 2002.

Marina, J. A. (2000). Teoría de la inteligencia creadora. Barcelona: Anagrama.

Crónicas de la Ultra Modernidad. Barcelona: Anagrama, Colección Argumentos.

Max-Neef, M.; Elizalde, A ; Hopenhayn, M. (1997). Desarrollo a escala humana. Santiago de Chile: Cepaur, 1986, Desarrollo a escala humana, en Eco-economía y Desarrollo, Ediciones de la Universidad, Buenos Aires.

Morin, E. (2007). El pensamiento complejo. Barcelona: Gedisa.

Nonaka, I.; Takeuchi, H. (1999). La organización creadora de conocimiento. Como las compañías japonesas crean la dinámica de la innovación. México: Oxford University Press.

Norman, D. (1989). Psychology of everyday things. N. York: Penguin books. . (1990). La psicología de los objetos cotidianos, Título original: The psycology of everyday things.

Basic Books, Editorial Nerea.

Peirce, Ch. S. (1974). La ciencia de la semiótica. Buenos Aires: Nueva Visión. (2008). El pragmatismo. Madrid: Encuentro.

Piaget, J. (1977). Adaptación vital y psicología de la Inteligencia. Buenos Aires: Editorial Psique. Poma, L. "La nueva competencia territorial”, en Boscherini, F. y Poma, L. (compiladores) (2000). Territorio Conocimiento y Competitividad de las empresas, El rol de las instituciones en el espacio global. Madrid: Miño y Dávila Editores.

Prahalad, C. K. (2010). The fortune at the bottom of the pyramid, Eradicating poverty through profit. EEUU: Wharton School Publishing.

Samaja, J. (2000). Semiótica y dialéctica, seguido de la lógica breve de Hegel. Buenos Aires: Episteme.

Epistemología de la salud, Reproducción social, subjetividad y transdisciplina (2004). Buenos Aires: Lugar Editorial.

Proceso, Diseño y Proyecto, en investigación científica, Cómo elaborar un proyecto sin confundirlo con el diseño y con el proceso. (2004). Buenos Aires: JVE Ediciones.

Samaja, J. A. (2016). "De la semiótica de la innovación a la semiótica de las mediaciones", XXX Jornadas de Investigación y XII Encuentro Regional SI+. Configuraciones, Acciones y relatos, FADU; UBA, Buenos Aires.

Rowe, P. G. (1994). Design thinking. London: MIT Press.

Rodríguez Barros, D., (2011), Diseño de productos y modelado 3D hiperealistico. Un caso de enseñanza y práctica proyectual en entornos digitales, XV Congreso Iberamericano de Gráfica Digital "Cultura aumentada", 
Evento Internacional. 16, 17, 18 noviembre 2011. Facultad de Arquitectura, Diseño y Urbanismo. Universidad Nacional del Litoral. Santa Fe. Argentina.

Schön, D. (1964). La formación de profesionales reflexivos, Hacia un nuevo diseño de la enseñanza y el aprendizaje en las profesiones. España: Paidós - Ministerio de Educación y Ciencia.

Simon, H. A. (1978). Las ciencias de lo artificial (título original: The science of the artificial), Colección Universitaria, traducido por Francisco Girondella, The Massachussets Institute of Technology. Barcelona: Editorial ATE.

Suarez Pasos, M. "Algunas reflexiones sobre la investigación-acción colaboradora en la educación”, en Revista electrónica de Enseñanza de las Ciencias (España: Universidad de Vigo: 2002, Vol. 1, pp. 40-56).

Torres Pernatele, M.: Trapaga Ortega, M. (2010). Responsabilidad Social de la Universidad. Buenos Aires: Paidós, Tramas sociales.

Vallaeys, F. "Etica y RSU, Reflexión crítica en torno a la ética aplicada a la Responsabilidad Social Universitaria", http://blog.pucp.edu.pe/item/5227/la-ecologia-de-la-accion-unconcepto-fundamental-para-pensar-laresponsabilidad-social,

(Ingreso 6-4-2011)

Vallaeys, F. "Responsabilidad social universitaria, una nueva filosofía de gestión ética para las universidades, Educación Superior y Sociedad", Nueva Epoca, año 13, Núm. 2, Setiembre del 2008. EES, Editor: Eve Vessuri. Caracas, 2008.

Vazquez Barquero, A.; Madoery, O. (2001). Transformaciones globales, instituciones políticas y desarrollo local. Rosario: Holo Sapiens.

Vygotski, L. S. (2000). El desarrollo de los procesos psicológicos superiores. Crítica: Barcelona.

Ynoub, R. C. (2010). De las matrices conjuntistas a las matrices organísmicas: aportes para ampliar la teoría de matrices de datos. [En elaboración] Waddington, C. H.

Abstract: The consideration of the word ideology in the context of design teaching refers to a hidden, covert content regarding the origins of the discipline, its functionality and convergence with the configuration of modern capitalist society. That hidden content is the complex network of links that unites the artifacts with the institutionality that sustains them, with the values and rules that govern social life, which assumed industry as a powerful device for production of values whose rationality was consubstantial to the idea of design, to its ethics and purpose, which was the extension of the benefits of science and technology to the population as a whole. Today, the fissures of this social configuration, imposes a new connection between practices and their meaning. But this concealment of meaning, that mutilation of contents, is made possible by some modes of teaching, which, in turn, tacitly or explicitly, are framed in epistemologies that prove to be insufficient. This article, which partially reproduces the ideas of the doctoral thesis "Reconstructing the framework of a creative society", gives an account of the first perceptions of the epistemological obstacles of the discipline to be inserted in contexts of 
complexity, to reconstruct the discipline as a research program, revealing their role in the reproduction of sustainable social life.

Key words: design - obstacle - sustainability - research - action - epistemology.

Resumo: A consideração da palavra ideologia no contexto do ensino do design faz referencia a um conteúdo oculto, encoberto, respeito às origens da disciplina, sua funcionalidade e convergência com a configuração da sociedade moderna capitalista. Esse conteúdo oculto é a complexa trama de ligações que une aos artefatos com a institucionalidade que os sustenta, com os valores e regras que regulam a vida social, que assumiu á indústria como dispositivo potente de produção de valores, cuja racionalidade foi consubstancial á ideia do design, a sua ética e finalidade, que era extensão dos benefícios da ciência e a tecnologia ao conjunto da população. Hoje, as fissuras desta configuração social impõe uma nova conexão entre as práticas e seu sentido. Mas esse ocultamento do sentido, essa mutilação de conteúdos, se faz possível por uns modos de ensino que á vez, tácita ou explicitamente, se enquadram em epistemologias que são insuficientes. Este artigo, que reproduz parcialmente ideias da tese de doutoramento "Reconstruindo a trama de uma sociedade criativa", da conta das primeiras percepções dos obstáculos epistemológicos da disciplina para se insertar em contextos de complexidade, reconstruir a disciplina como programa de pesquisa, revelando seu papel na reprodução da vida social sustentável.

Palavras chave: design - obstáculo - sustentabilidade - pesquisa-ação - epistemologia.

Reconstruyendo el entramado de una sociedad creativa. Estrategias para la formación de diseñadores en contextos de complejidad fue publicado de la página 63 a página100 en Cuadernos del Centro de Estudios de Diseño y Comunicación № 67 